\title{
Spectroscopy and photophysics of 4- and 7-hydroxycoumarins and their thione analogs
}

\author{
J. Seixas de Melo*, P.F. Fernandes \\ Department of Chemistry, University of Coimbra, 3004-535 Coimbra, Portugal
}

Received 31 August 2000; revised 28 November 2000; accepted 28 November 2000

\begin{abstract}
Acid-base equilibria were studied for 4-hydroxycoumarin, 7-hydroxy-4-methylcoumarin and their thione derivatives in different media for their ground and lowest energy singlet and triplet excited states. The ethoxylated and/or methoxylated derivatives were also investigated. Characterization involves fluorescence spectra, quantum yields, lifetimes, phosphorescence spectra, lifetimes, and triplet-triplet absorption spectra. From their $\mathrm{p} K_{\mathrm{a}}$ values it was found that 4 and 7 -hydroxycoumarins are more acidic in their lowest excited singlet states than in $\mathrm{S}_{0}$. The origin and character of the lowest singlet and triplet excited states is discussed. (c) 2001 Elsevier Science B.V. All rights reserved.
\end{abstract}

Keywords: Coumarins; Photophysics; Singlet state; Triplet state; Fluorescence; Phosphorescence

\section{Introduction}

Coumarins, in particular the hydroxycoumarins (HCs), are well-known natural products [1], but they also occur in areas as diverse as sun screen formulations [2], laser dyes [3], pesticides, etc [4]. Despite the enormous potential interest of these compounds there is no complete characterization of their photophysics.

In this work, we report the properties of 4 and 7 $\mathrm{HCs}$, their ethers and their thione analogs in their $\mathrm{S}_{0}$, $\mathrm{S}_{1}$ and $\mathrm{T}_{1}$ states (Scheme 1). Ground and excited state acid-base behavior was studied, and absorption assigned to neutral, anionic and cationic forms. The absence of fluorescence for the thionecoumarins indicates very efficient radiationless deactivation. In some cases more complex tautomeric behavior was

\footnotetext{
* Corresponding author. Tel.: +351-39-852-080; fax: +351-39827-703.

E-mail address: sseixas@ci.uc.pt (J. Seixas de Melo).
}

observed [5-8]. This will be described in detail elsewhere [9].

The overall excited state formation and deactivation pathways for the $\mathrm{HC}$ are summarized in Scheme 2. Depending on the HC considered, some of the pathways can be neglected.

\section{Experimental}

All used solvents were of spectroscopic grade and were purified by conventional methods. Millipore water was generally used. Glass compositions are given in volume:volume ratios. 4-Hydroxycoumarin and 4-methoxycoumarin were used as purchased (extrasynthese). 7-Methoxy-4-methylcoumarin (Aldrich) and 7-hydroxy-4-methylcoumarin (Aldrich) were purified as reported elsewhere [10]. The thione coumarins were synthetized by conventional procedures $[9,11]$. Absorption and luminescence spectra were recorded on Shimadzu UV-2100, Olis-Cary 14, and Jobin-Ivon 
<smiles></smiles>

$\mathrm{X}=\mathrm{H}, \mathrm{Y}=\mathrm{OH}, \mathrm{Z}=\mathrm{O}, \quad 4 \mathrm{HC}$

$\mathrm{X}=\mathrm{H}, \mathrm{Y}=\mathrm{OCH}_{3}, \mathrm{Z}=\mathrm{O}$, 4MetC

$\mathrm{X}=\mathrm{H}, \mathrm{Y}=\mathrm{OH}, \mathrm{Z}=\mathrm{S}, \quad 4 \mathrm{HTC}$

$\mathrm{X}=\mathrm{H}, \mathrm{Y}=\mathrm{OC}_{2} \mathrm{H}_{5}, \mathrm{Z}=\mathrm{S}, 4 \mathrm{Et} \underline{\mathrm{TC}}$

$\mathrm{X}=\mathrm{OH}, \mathrm{Y}=\mathrm{H}, \mathrm{Z}=\mathrm{O}, \quad 7 \mathrm{H} 4 \mathrm{MC}$

$\mathrm{X}=\mathrm{OCH}_{3}, \mathrm{Y}=\mathrm{H}, \mathrm{Z}=\mathrm{O}, 7 \mathrm{Met} 4 \mathrm{MC}$

$\mathrm{X}=\mathrm{OH}, \mathrm{Y}=\mathrm{H}, \mathrm{Z}=\mathrm{S}, \quad$ 7H4MTC

$\mathrm{X}=\mathrm{OC}_{2} \mathrm{H}_{5}, \mathrm{Y}=\mathrm{H}, \mathrm{Z}=\mathrm{S}, 7 \mathrm{Et} 4 \mathrm{MTC}$

\section{Scheme 1.}

SPEX Fluorog 3-22 spectrometers, respectively. For phosphorescence studies, the $1934 \mathrm{D}$ phosphorimeter accessory was used. Fluorescence and phosphorescence spectra were corrected for the wavelength response of the system. Oscillator Strengths were obtained from the experimental integrated intensities, according to equation: $f=4.315 \times 10^{-9} \int \epsilon(\bar{\nu}) d \bar{\nu}$.

Triplet-triplet absorption spectra and intersystem crossing (ISC) yields were obtained using an Applied Photophysics laser flash photolysis equipment pumped by a Nd:YAG laser (Spectra Physics) with excitation wavelength $355 \mathrm{~nm}$ or $266 \mathrm{~nm}$ [9]. First- order kinetics was observed for the decay of the lowest triplet state. The transient spectra (300$700 \mathrm{~nm}$ ) were obtained by monitoring the optical density change at 5-10 nm intervals and averaging at least 10 decays at each wavelength.

Fluorescence decays were measured using a homebuilt TCSPC apparatus with an $\mathrm{N}_{2}$ filled IBH 5000 coaxial flashlamp as excitation source, Jobin-Ivon monochromator, Philips XP2020Q photomultiplier, and Canberra instruments TAC and MCA. Alternate measurements (1000 c.p.c.) of the pulse profile at $337 \mathrm{~nm}$ and the sample emission were performed until $1-2 \times 10^{4}$ counts at the maximum were reached. The fluorescence decays were analyzed using the modulating functions method of Striker with automatic correction for the photomultiplier "wavelength shift" [12].

The semi-empirical quantum mechanical calculations were performed with the ZINDO/S Hamiltonian [13] using HYPERCHEM (release 3, for Windows). Up to 201 singly excited configurations were used in the configuration interaction (CI) calculations.

\section{Results}

\section{1. $4 H C$ and $4 M e t C$}

Fig. 1A presents the absorption, fluorescence and

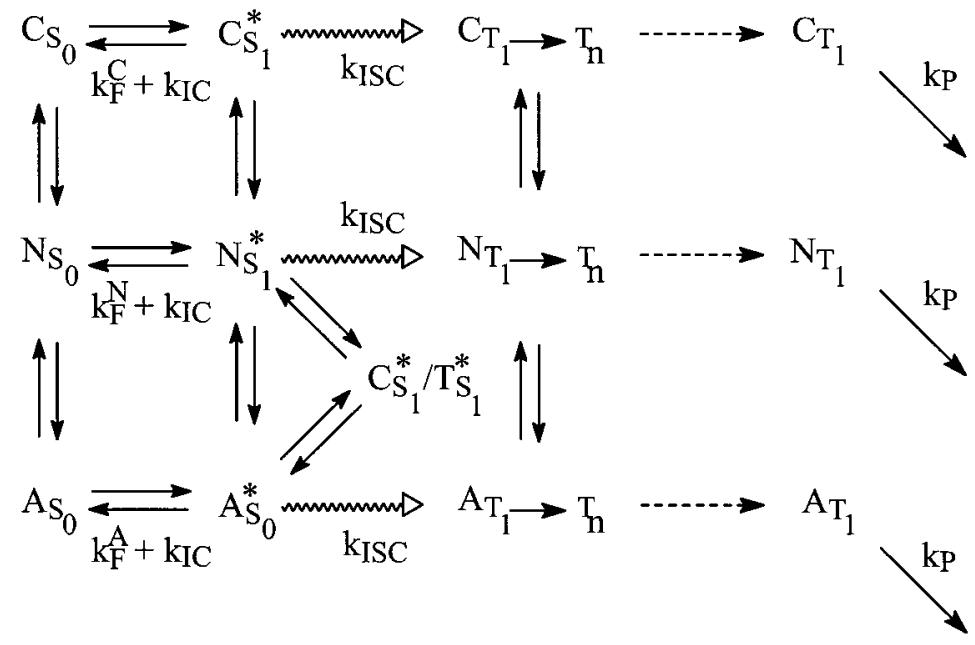



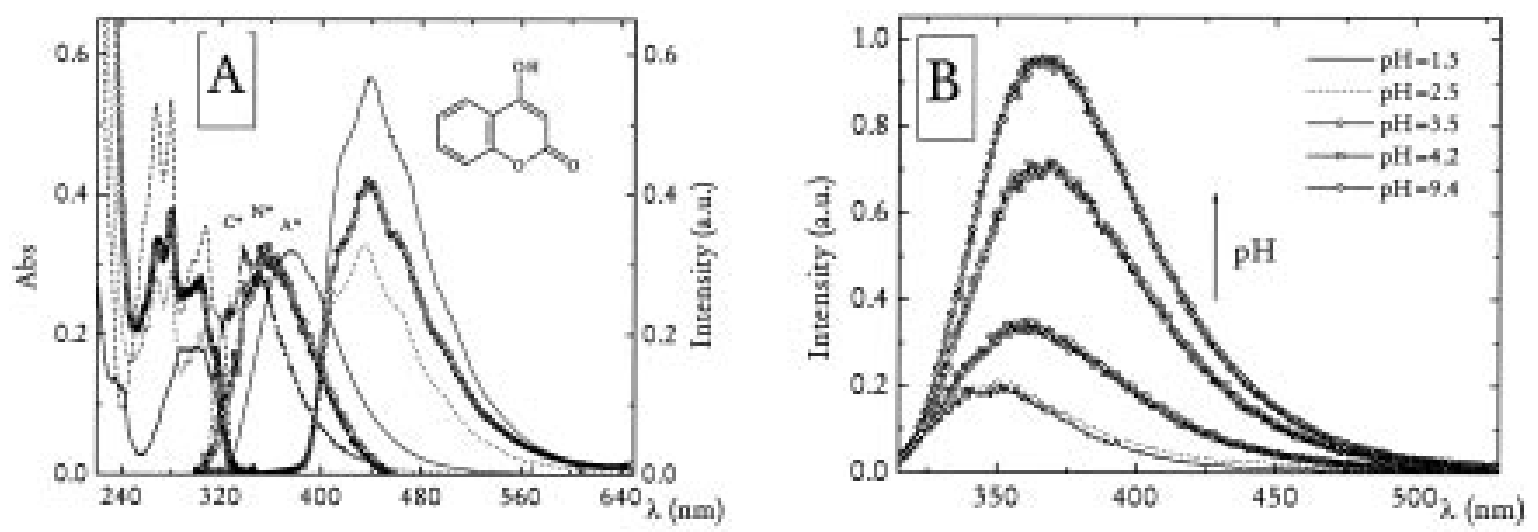

Fig. 1. (A) Left-hand panel, absorption spectra of 4HC, middle-hand panel, fluorescence spectra of and right-hand panel, phosphorescence spectra of $4 \mathrm{HC}$ in ethanol (-O-), ethanol: $\mathrm{HCl}(\ldots)$, ethanol: diethyl ether: $\mathrm{NH}_{3}(-)$ and dioxane [only for absorption (- - -)]. (B) Fluorescence spectra of $4 \mathrm{HC}$ as a function of $\mathrm{pH}$.

phosphorescence spectra of 4-hydroxycoumarin (4HC) in the solvents: ethanol, ethanol: $\mathrm{HCl}(37 \%$ in water) 19:1 (v:v) and ethanol: diethyl ether: $\mathrm{NH}_{3}$ (28\% in water) 10:9:1. In water (figure not shown), for $\mathrm{pH}<4$ the spectra presents two vibrationally resolved bands at 280 and $300 \mathrm{~nm}$. For $\mathrm{pH}>4$ new bands appear at 286 and $298 \mathrm{~nm}$. In aprotic solvents (e.g. dioxane) the absorption spectra of $4 \mathrm{HC}$ is equal in shape and has similar maxima to these obtained for water at $\mathrm{pH}<4$. This absorption was therefore attributed to a neutral species. The other absorbing form, also obtained in basic ethanolic mixtures, was attributed to the anionic form of $4 \mathrm{HC}$.

The emission spectrum of $4 \mathrm{HC}$ in water (Fig. 1B) lacks structure, and for $\mathrm{pH}<3$ has a maximum at $\lambda_{\mathrm{em}}^{\max }=350 \mathrm{~nm}$. The emission maximum shifts to $360 \mathrm{~nm}(3<\mathrm{pH}<4)$ and for $\mathrm{pH} \geq 4$, the maximum is at $\lambda_{\mathrm{em}}^{\max }=370 \mathrm{~nm}$. The observed $\mathrm{pH}$ dependent maxima probably imply the presence of three different species: a cation, $\mathrm{C}^{*}$, with $\lambda_{\mathrm{em}}^{\max }=350 \mathrm{~nm}$, a neutral form, $\mathrm{N}^{*}$, $\lambda_{\mathrm{em}}^{\max }=360 \mathrm{~nm}$, and an anion, $\mathrm{A}^{*}, \lambda_{\mathrm{em}}^{\max }=370 \mathrm{~nm}$.

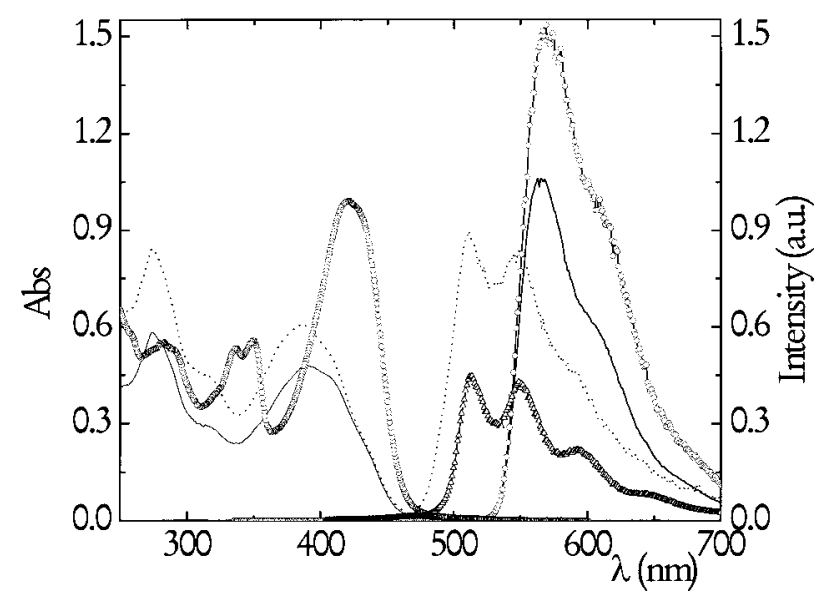

Fig. 2. Left-hand panel, absorption spectra of $4 \mathrm{HTC}$ and right-hand panel, phosphorescence spectra of $4 \mathrm{HTC}$ in ethanol (-), ethanol:HCl (- - -) and ethanol:diethyl ether: $\mathrm{NH}_{3}(-\mathrm{O}-)$. In right-hand panel also presented is the phosphorescence spectrum of $4 \mathrm{Et} T \mathrm{C}$ in ethanol (- $\triangle$-). 


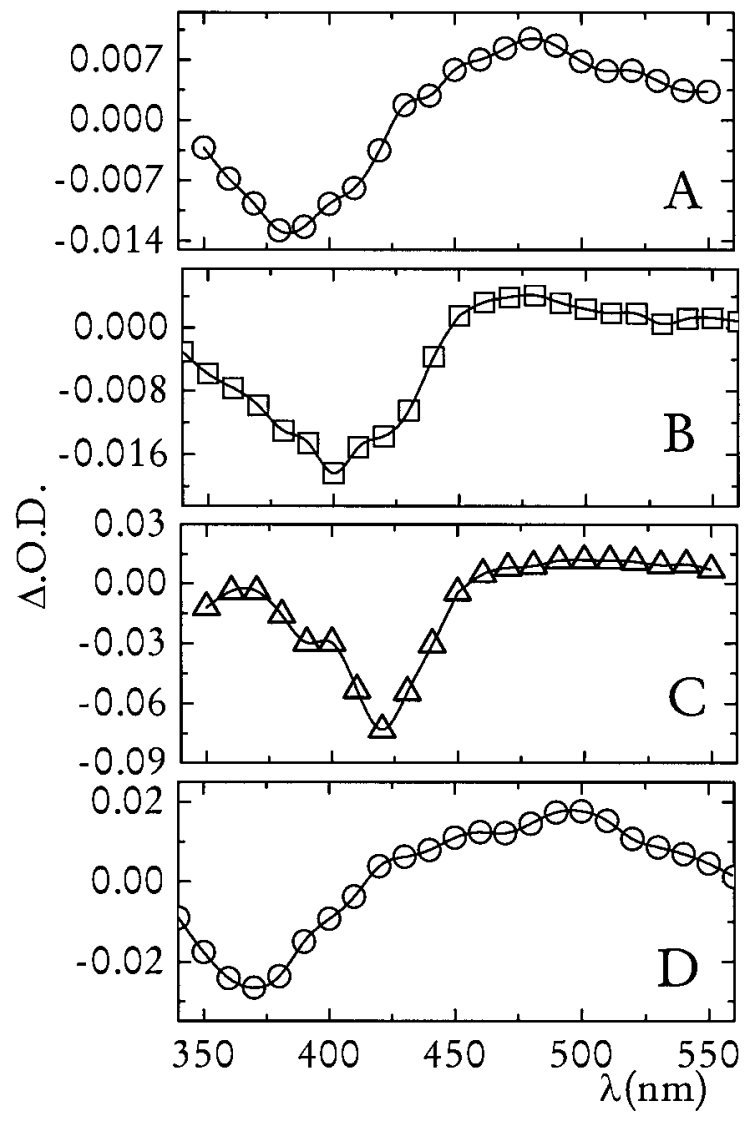

Fig. 3. Triplet-triplet spectra of $4 \mathrm{HTC}$ in (A) benzene collected $0.2 \mu \mathrm{s}$ after the flash, (B) ethanol collected $0.3 \mu \mathrm{s}$ after the flash, (C) ethanol: diethyl ether: $\mathrm{NH}_{3}$ collected $1 \mu \mathrm{s}$ after the flash and of $4 \mathrm{EtTC}$ in (D) benzene collected $0.3 \mu \mathrm{s}$ after the flash.

The obtained $\mathrm{p} K_{\mathrm{a}}^{*}=3.7$, for the $\mathrm{N}^{*} \longleftrightarrow \mathrm{A}^{*}$ equilibrium was determined by fluorimetric titration. Comparison of the emission spectra in aqueous solution (Fig. 1B) and in the ethanolic mixtures (Fig. 1A) shows a blue shift of the emission band for all three species: $\mathrm{C}^{*}\left(\lambda_{\mathrm{em}}^{\max }=340 \mathrm{~nm}\right), \mathrm{N}^{*}$ $\left(\left(\lambda_{\mathrm{em}}^{\max }=355 \mathrm{~nm}\right)\right.$ and $\mathrm{A}^{*}\left(\lambda_{\mathrm{em}}^{\max }=375 \mathrm{~nm}\right)$. Also, in the ethanolic mixtures $\mathrm{C}^{*}$ and $\mathrm{N}^{*}$ emission presents vibrational structure. In the three ethanolic mixtures (figure not shown), the parent compound 4MetC shows a similar emission with $\lambda_{\mathrm{em}}^{\max }=350 \mathrm{~nm}$, identified with the neutral form of 4HC. This suggests the cationic form of $4 \mathrm{HC}$ being protonated at the hydroxylic rather than carbonyl oxygen.

\section{2. $4 H T C$ and $4 E t T C$}

Fig. 2 presents the absorption and phosphorescence spectra of 4-hydroxythionecoumarin (4HTC) in three different ethanolic solvents, together with the phosphorescence of 4EtTC in ethanol. For 4EtTC, a single vibrationally resolved band is observed with $\lambda_{\mathrm{em}}^{\max }=550 \mathrm{~nm}$ independent of solvent. Fig. 3 shows the triplet-triplet spectra of $4 \mathrm{HTC}$ and $4 \mathrm{EtTC}$ in different solvents.

\subsection{H4MC, 7H4MTC and their parent compounds 7Met4MC and 7Et4MTC}

The absorption spectra of 7H4MC consist of two different bands, attributed to the neutral and anionic forms, $\mathrm{N}$ and $\mathrm{A}$, respectively $[5,7,8]$. In fluorescence, an additional band with $\lambda_{\mathrm{em}}^{\max } \approx 480 \mathrm{~nm}$ is also observed [5,6]. The nature of this new band as been extensively discussed, but must be considered to be a neutral tautomer [5,6]. Triplet-triplet spectra of 7H4MC, 7Met4MC, 7H4MTC and 7Et4MTC in different solvents are shown in Fig. 4.

Fig. 5A presents the absorption and phosphorescence spectra of 7H4MTC in different ethanolic solvents, while Fig. 5B presents the $\mathrm{pH}$ dependence of the absorption spectra.

\section{Discussion}

The only previous reports on the spectroscopy and photophysics on these systems are for the $S_{1}$ state of $7 \mathrm{H} 4 \mathrm{MC}[3,5-8]$ and transient spectra for $4 \mathrm{HC}$ at $77 \mathrm{~K}$ and $7 \mathrm{H} 4 \mathrm{MC}$ at room temperature [14-16].

The following discussion will focus on: (a) the assignment of the lowest singlet and triplet states $\left(\mathrm{n}, \pi^{*}\right.$ vs $\left.\pi, \pi^{*}\right)$; (b) the influence of solvent on the emission; (c) the nature of the coupling mediating $\mathrm{S}_{1}-\mathrm{T}_{1}$ ISC and (d) the number and type of species existing in $S_{0}, S_{1}$ and $T_{1}$.

\subsection{Acidity in the $S_{0}$ and $S_{1}$ states}

Table 1 presents the $\mathrm{p} K_{\mathrm{a}}$ and $\mathrm{p} K_{\mathrm{a}}^{*}$ values for the studied compounds. Substitution in the 4 and 7 positions induces different behavior relative to the parent thiones. With $4 \mathrm{HC}$ vs $4 \mathrm{HTC}$ an increase of three $\mathrm{p} K_{\mathrm{a}}$ units is obtained. However, for $7 \mathrm{H} 4 \mathrm{MC}$ vs $7 \mathrm{H} 4 \mathrm{MTC}$ 

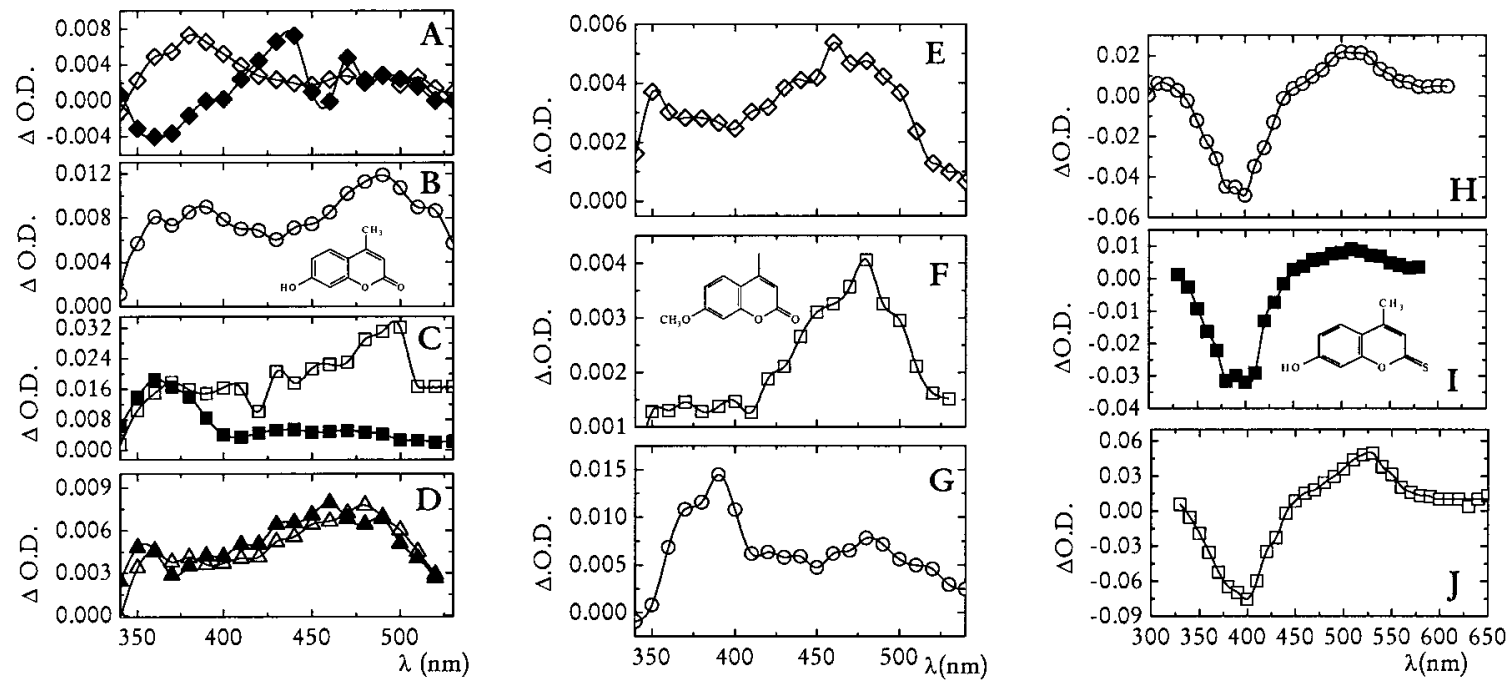

Fig. 4. Left-hand panel, triplet-triplet spectra of 7H4MC in (A) ethanol (- $\left.-_{-}\right)$collected $0.5 \mu \mathrm{s}$ after the flash and water at $\mathrm{pH}=11.5\left(-\bullet_{-}\right)$ collected $1.5 \mu$ s after the flash, (B) ethanol: $\mathrm{HCl}$ collected $1.5 \mu \mathrm{s}$ after the flash, (C) dioxane:water mixture 4:1 (- $\square-$ ) and dioxane:water mixture

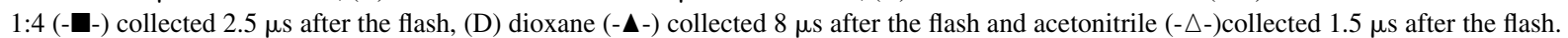
Middle-hand panel, triplet-triplet spectra of 7Met4MC in (E) dioxane collected 1.5 $\mu$ s after the flash, (F) dioxane:water mixture 4:1 collected $7 \mu \mathrm{s}$ after the flash and $(\mathrm{G})$ dioxane:water mixture 1:4 collected $0.2 \mu \mathrm{s}$ after the flash. Right-hand panel, triplet-triplet spectra of (H) $7 \mathrm{HMTC}$ in methanol collected $0.1 \mu \mathrm{s}$ after the flash, (I) 7HMTC in benzene collected $0.1 \mu \mathrm{s}$ after the flash and (J) 7Et4MTC in benzene collected $0.1 \mu \mathrm{s}$ after the flash.

this difference is reduced to one unit, and the thione now has lower $\mathrm{p} K_{\mathrm{a}}$ than the oxygen derivatives. The change is more dramatic for the $\mathrm{p} K_{\mathrm{a}}$ values of $7 \mathrm{H} 4 \mathrm{MC}$ where a difference of ca. eight orders of magnitude is found when going from $S_{0}$ to $S_{1}$. In

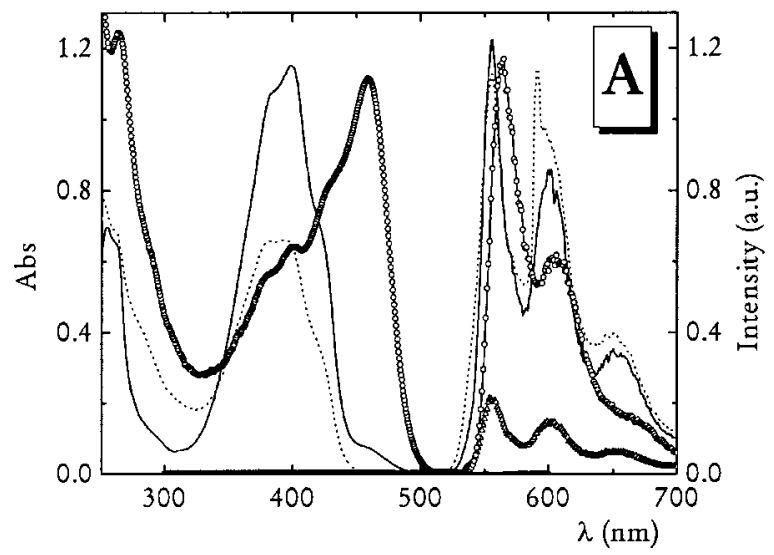

the literature identical $\mathrm{p} K_{\mathrm{a}}$ and $\mathrm{p} K_{\mathrm{a}}^{*}$ are given for $4 \mathrm{HC}$ [17]. The lack of significant difference between ground and excited state $\mathrm{p} K_{\mathrm{a}} \mathrm{s}$, for $4 \mathrm{HC}$, may explain why tautomerism is observed in the $\mathrm{S}_{1}$ state of $7 \mathrm{H} 4 \mathrm{MC}$ but not in $4 \mathrm{HC}$.

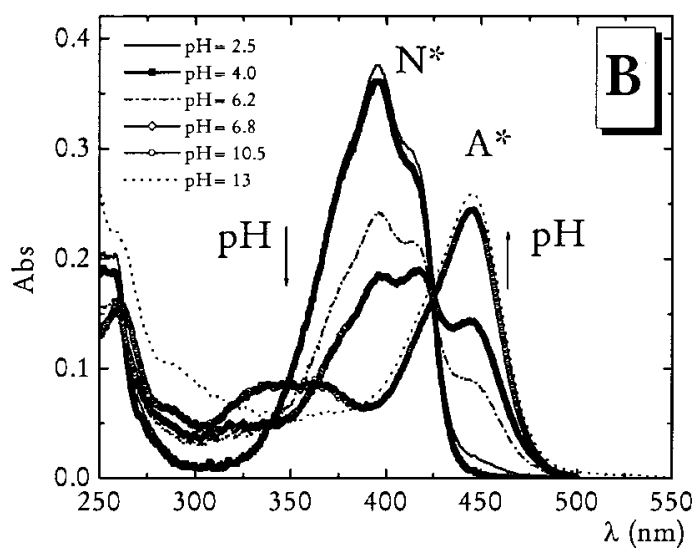

Fig. 5. (A) Left-hand panel, absorption spectra of 7H4MTC and right-hand panel, phosphorescence spectra of 7H4MTC in ethanol (-), ethanol: $\mathrm{HCl}(--)$ and ethanol:diethyl ether: $\mathrm{NH}_{3}$ (-O-). In right-hand panel also presented is the phosphorescence spectrum of 7Et4MTC in ethanol $(-\triangle-)$. (B) Absorption spectra of $7 \mathrm{H} 4 \mathrm{MTC}$ as a function of $\mathrm{pH}$. 
Table 1

Values of $\mathrm{p} K_{\mathrm{a}}$ and $\mathrm{p} K_{\mathrm{a}}^{*}$ for the different $\mathrm{HCs}$

\begin{tabular}{lll}
\hline Compound & $\mathrm{p} K_{\mathrm{a}}$ & $\mathrm{p} K_{\mathrm{a}}^{*}$ \\
\hline $4 \mathrm{HC}$ & $4.2 \leq \mathrm{p} K_{\mathrm{a}} \leq 4.3$ & $3.6 \leq \mathrm{p} K_{\mathrm{a}}^{*} \leq 3.7$ \\
4HTC & $7.3 \leq \mathrm{p} K_{\mathrm{a}} \leq 7.5$ & - \\
$7 \mathrm{H} 4 \mathrm{MC}$ & $7.7 \leq \mathrm{p} K_{\mathrm{a}} \leq 7.8$ & $\mathrm{p} K_{\mathrm{a}}^{*}=0.74$ \\
7H4MTC & $6.8 \leq \mathrm{p} K_{\mathrm{a}} \leq 7.0$ & - \\
\hline
\end{tabular}

\subsection{Triplet states}

\subsubsection{Nature of the lowest triplet state, $T_{1}$}

Assignment of triplet state configurations [18] is based upon: (1) the relatively large gap, $\Delta E_{\mathrm{ST}}$, between the lowest singlet and emitting triplet when $\mathrm{T}_{1}$ is $\mathrm{n}, \pi^{*}$; and (2) characteristic phosphorescence lifetimes $\left(\tau_{\mathrm{Ph}}<0.01 \mathrm{~s}\right.$, for $\mathrm{n}, \pi^{*}$ states and seconds for $\pi, \pi^{*}$ states).

From the observed phosphorescence lifetimes (Table 2), $T_{1}$ has $\pi, \pi^{*}$ character for all the carbonyl compounds whilst for the thiones it is $n, \pi^{*}$. This appears to be independent of the state of protonation. Also, the relatively large energy gap between the lowest singlet and the emitting triplet, $\Delta E_{\mathrm{ST}}$, suggests $\mathrm{a}^{3}\left(\pi, \pi^{*}\right)$ state. Smaller values for $\Delta E_{\mathrm{ST}}$ are associated with ${ }^{3}\left(n, \pi^{*}\right)$ states. Exceptional behavior was observed for $7 \mathrm{H} 4 \mathrm{MTC}$, where the short $\tau_{\mathrm{Ph}}$ clearly shows ${ }^{3}\left(\mathrm{n}, \pi^{*}\right)$ character for $\mathrm{T}_{1}$ but $\Delta E_{\mathrm{ST}}$ is relatively large. This may de due to the small $\mathrm{T}_{1}-\mathrm{T}_{2}$ gap, lending some $\pi, \pi^{*}$ character to $T_{1}$, according to ISC $\mathbf{I}$ in Scheme 2 (see next section).

\subsubsection{Mechanisms of intersystem crossing}

The following ISC pathways can be observed (Scheme 3), for the different studied coumarins, depending on the nature of the $S_{1}$ and $T_{1}$ states. For the thionecoumarins, since $S_{1}$ and $T_{1}$ both are $n, \pi^{*}$, the pathway of ISC should occur via the spin orbital coupling $\left(H_{\mathrm{SO}}\right)$ and vibrational coupling operators $\left(H_{\mathrm{Vib}}\right)$, I. For the carbonyl compounds two mechanisms can operate, II or III in Scheme 3.

\subsection{Nature of the lowest singlet excited state, $S_{1}$}

Generally if a carbonyl or a thiocarbonylcontaining molecule has a lowest $S_{n, \pi^{*}}$ state, it will only be weakly fluorescent. The absence of fluorescence of thiones is generally accepted to be due to very efficient radiationless deactivation [19], where $T_{1}$ is populated with close to unit efficiency, but also with some efficient internal conversion from $S_{1}$. For 6methylthionecoumarin and thionecoumarin, which has lowest $n, \pi^{*}$ singlet states, values of $\phi_{T}=0.75$ and 1.0, respectively, were obtained in benzene $[11,20]$.

For the carbonyl compounds, the origin of the lowest singlet excited state strongly depends on the nature of the solvent. With 7H4MC and its methoxylated compound a $S_{1} n, \pi^{*}$ state is observed in nonpolar solvents, but $S_{1}$ is $\pi, \pi^{*}$ in polar solvents [10]. For $4 \mathrm{HC}$, based on $\tau_{\mathrm{F}}$ and $\phi_{\mathrm{F}}$ data it is also $\mathrm{n}, \pi^{*}$. In dioxane:water mixtures quenching of the neutral form is observed, with lifetimes changing from $0.83 \mathrm{~ns}$

Table 2

Phosphorescence lifetimes, $\tau_{\mathrm{Ph}}$, in seconds, in four different solvents for the coumarins studied. Also presented is the nature of the $\mathrm{T}_{1}$ state and the singlet-triplet splitting

\begin{tabular}{|c|c|c|c|c|c|}
\hline Compound & Ethanol & Ethanol:HCl & Ethanol:ether: $\mathrm{NH}_{3}$ & $\mathrm{MCH}$ & $\Delta E_{\mathrm{ST}}^{\mathrm{a}}\left(\mathrm{cm}^{-1}\right)$ \\
\hline $4 \mathrm{HC}$ & $1.43 \pi, \pi^{*}$ & $1.53 \pi, \pi^{*}$ & $0.61 \pi, \pi^{*}$ & $-\left({ }^{b}\right)$ & $\approx 4000$ \\
\hline $4 \mathrm{MetC}$ & $1.27 \pi, \pi^{*}$ & $1.41 \pi, \pi^{*}$ & $1.31 \pi, \pi^{*}$ & $1.12 \pi, \pi^{*}$ & \\
\hline $4 \mathrm{HTC}$ & $0.0052 \mathrm{n}, \pi^{*}$ & $0.0023 \mathrm{n}, \pi^{*}$ & $0.0053 \mathrm{n}, \pi^{*}$ & $-\left({ }^{b}\right)$ & $\approx 900$ \\
\hline $4 \mathrm{Et} T \mathrm{C}$ & $0.001 \mathrm{n}, \pi^{*}$ & $0.0012 \mathrm{n}, \pi^{*}$ & $0.00124 \mathrm{n}, \pi^{*}$ & $0.00083 \mathrm{n}, \pi^{*}$ & \\
\hline 7H4MC & $1.65 \pi, \pi^{*}$ & $1.69 \pi, \pi^{*}$ & $2.26 \pi, \pi^{*}$ & $-\left({ }^{b}\right)$ & $\approx 6000$ \\
\hline $7 \mathrm{Met} 4 \mathrm{MC}$ & $1.41 \pi, \pi^{*}$ & $1.77 \pi, \pi^{*}$ & $1.49 \pi, \pi^{*}$ & $1.47 \pi, \pi^{*}$ & \\
\hline 7H4MTC & $0.0006 \mathrm{n}, \pi^{*}$ & $0.0009 \mathrm{n}, \pi^{*}$ & $0.01 \mathrm{n}, \pi^{*}$ & $-\left({ }^{b}\right)$ & $\approx 2700$ \\
\hline 7Et4MTC & $0.00045 \mathrm{n}, \pi^{*}$ & $0.00041 \mathrm{n}, \pi^{*}$ & $0.00054 \mathrm{n}, \pi^{*}$ & $0.00056 \mathrm{n}, \pi^{*}$ & \\
\hline
\end{tabular}

\footnotetext{
a Obtained by taken the energy of the on set of the absorption and phosphorescence bands. For the methoxylated or ethoxylated parent compounds identical values were found.

${ }^{\mathrm{b}}$ Not soluble in this solvent.
} 


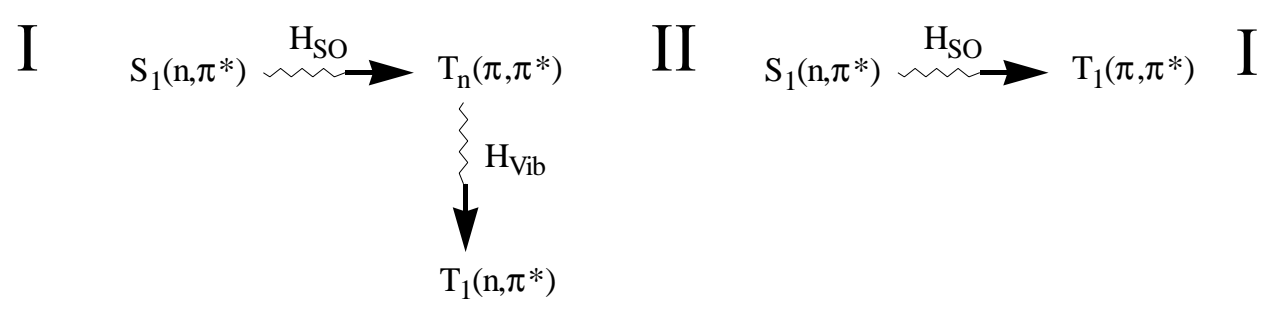

Scheme 3.

(dioxane:water 4:1 v/v) to $0.2 \mathrm{~ns}$ (water, $\mathrm{pH}=5.5$ ). In cases where anion is present a second slightly solvent dependent lifetime is obtained $\left(\tau_{\mathrm{F}} \approx 5.5 \mathrm{~ns}\right)$. The obtained $\phi_{\mathrm{F}}$ values, ranging from 0.0016 (dioxane) to 0.018 (water, $\mathrm{pH}=5.5$ ), leading to $k_{\mathrm{F}}$ values from $0.016 \mathrm{~ns}^{-1}$ (in dioxane $\tau_{\mathrm{F}} \leq 0.1 \mathrm{~ns}$ ) to $0.1 \mathrm{~ns}^{-1}$, are consistent with a lowest lying ${ }^{1}\left(\mathrm{n}, \pi^{*}\right)$ state vibronically mixed to a close upper ${ }^{1}\left(\pi, \pi^{*}\right)$ state.

\subsection{Comparison with theory}

Comparison of predicted and experimental spectral data is given in Table 3. For the thione coumarins, longer wavelength transitions $n, \pi^{*}$ are predicted. For aromatic thione compounds this is common and shown as a dipole-electric forbidden $\mathrm{n}, \pi^{*}$ transition with very low molar extinction coefficients [19]. The absence of fluorescence emission supports a lowest $\mathrm{n}, \pi^{*}$ singlet. Although this was not observed, transition energy for the $n \rightarrow \pi^{*}$ transition is probably found in the region predicted by calculation.

\subsection{Absorbing and emitting tautomers}

\subsection{1. $4 \mathrm{HC}$ and $4 E t C$}

In the ground state $4 \mathrm{HC}$ presents an acid-base equilibria between neutral (N) and anionic (A) forms (Fig. 1), with the A absorption at shorter wavelengths than N. Hydroxyl substitution in the position 4, of the coumarin skeleton, has a marked influence on the $S_{1}$ energy of $\mathrm{N}$ and $\mathrm{A}$. As with other coumarins [10] conjugative substitution, e.g. by $\mathrm{OH}$ groups, is predicted to blue shift singlet $n, \pi^{*}$ transitions and red shift singlet $\pi, \pi^{*}$ transitions [18]. This is probably due to the perturbation introduced by $\mathrm{n}$ electrons of the hydroxyl group, which in the deprotonated form cannot be shared by the aromatic ring. Fluorescence emission from pure neutral, cationic and anionic forms, respectively, is observed for $4 \mathrm{HC}$, in neutral, acidic and alkaline glasses, as confirmed by monoexponential decays. With phosphorescence, similar spectra are observed in the three mixtures, indicating that a single species is responsible for the emission from $\mathrm{T}_{1}$ (Fig. 1A). However, the different lifetimes $\left(\tau_{\mathrm{Ph}}=1.43 \mathrm{~s}\right.$

Table 3

Experimental and theoretical data for the first two lowest transition energy $\left(\mathrm{S}_{1,2} \leftarrow \mathrm{S}_{0}\right)$ and oscillator strength, $f$, for the coumarins studied

\begin{tabular}{|c|c|c|c|c|c|c|}
\hline Compound $^{\mathrm{a}}$ & Transition & $\lambda(\mathrm{nm}) \mathrm{ZINDO}-\mathrm{CI} / \mathrm{S}$ & $f$ (theory) & $\lambda^{\max }(\mathrm{nm})($ exp. $)$ & $\epsilon\left(\mathrm{M}^{-1} \mathrm{~cm}^{-1}\right)$ & $f($ exp.) \\
\hline \multirow[t]{2}{*}{$4 \mathrm{HC}$} & $\mathrm{S}_{0} \rightarrow \mathrm{S}_{1}$ & $312\left(\mathrm{n}, \pi^{*}\right)$ & 0.0007 & & & \\
\hline & $\mathrm{S}_{0} \rightarrow \mathrm{S}_{2}$ & 284 & 0.2406 & 304 & 19,500 & 0.174 \\
\hline \multirow[t]{2}{*}{$4 \mathrm{HTC}$} & $\mathrm{S}_{0} \rightarrow \mathrm{S}_{1}$ & $432\left(n, \pi^{*}\right)$ & 0.0004 & & & \\
\hline & $\mathrm{S}_{0} \rightarrow \mathrm{S}_{2}$ & 312 & 0.5579 & 395 & 6780 & 0.148 \\
\hline \multirow[t]{3}{*}{ 7H4MC } & $\mathrm{S}_{0} \rightarrow \mathrm{S}_{1}$ & $319(328)^{\mathrm{b}}$ & $0.0101\left(2 \times 10^{-3}\right)^{\mathrm{b}}$ & & & \\
\hline & $\mathrm{S} 0 \rightarrow \mathrm{S} 2$ & $294(314)^{b}$ & $0.4119(0.1025)^{\mathrm{b}}$ & 317 & 9500 & \\
\hline & $\mathrm{S}_{0} \rightarrow \mathrm{S}_{3}$ & $278(285)^{\mathrm{b}}$ & $0.0932(0.1532)^{\mathrm{b}}$ & 275 & 5550 & \\
\hline \multirow[t]{2}{*}{ 7Et4MTC } & $\mathrm{S}_{0} \rightarrow \mathrm{S}_{1}$ & $477\left(\mathrm{n}, \pi^{*}\right)$ & 0.0017 & & & \\
\hline & $\mathrm{S}_{0} \rightarrow \mathrm{S}_{2}$ & 332 & 0.5507 & 385 & 17,881 & \\
\hline
\end{tabular}

\footnotetext{
${ }^{a}$ No significant differences were found for alkoxy or hydroxycoumarins.
}

${ }^{\mathrm{b}}$ Obtained with the CNDO/S-CI method. 
(ethanol), $1.53 \mathrm{~s}$ (ethanol:HCl) and $0.61 \mathrm{~s}$ (ethanol:ether: $\left.\mathrm{NH}_{3}\right)$ ) suggest that in basic media either a different species might be present, or these are quenched by $\mathrm{NH}_{3}$. With the parent $4 \mathrm{MetC}$ a single phosphorescent band is observed with $\lambda_{\mathrm{em}}^{\max }=445 \mathrm{~nm}$ and $\tau_{\mathrm{ph}}=1.3 \pm 0.1 \mathrm{~s}$ independent of solvent/mixture (Table 2).

For the cationic species in $S_{1}$, protonation is possible at three different sites. Since the spectrum of the methoxylated compound is independent of solvent matrix, protonation is most probably at the hydroxyl oxygen. Literature data exists on the presence of three species in $\mathrm{S}_{0}$ and $\mathrm{S}_{1}$ [21,22]. However, the assignment of the emitting species is questionable, since it is suggested that at $\mathrm{pH}=2.4 \mathrm{a}$ neutral excited species exists, while the cationic species is only reported for very strong acidic media [21]. Comparison with our data shows that the species attributed to $\mathrm{N}^{*}$ may actually be considered the excited cation, $\mathrm{C}^{*}$. Also the same authors suggest that their cationic excited species $\left(\lambda_{\mathrm{em}}^{\max }=386 \mathrm{~nm}\right)$ is formed by protonation of the carbonyl group. It is possible that under the strong acid conditions used a new cationic excited species arises, which is different from ours. Although the likely protonation site of $4 \mathrm{HC}$ in $S_{1}$ is the carbonyl oxygen, the hydroxyl and lactone oxygens cannot be excluded.

Although difficulties exist in detailed analysis of the triplet-triplet spectra of 4HC (figure not shown) because of low absorption, and solvent influence, studies of 4MetC allow assignment of the neutral triplet state, and this is supported by phosphorescence lifetimes.

\subsection{2. $4 H T C$ and $4 E t T C$}

The absorption spectrum of $4 \mathrm{HTC}$ in basic ethanol show a band $\left(\lambda_{\max }=420 \mathrm{~nm}\right)$ attributed to the anion that is only observed at very high $\mathrm{pH}$ (Fig. 2). Also, note that the absorption band in the acidified mixture $\left(\lambda_{\max }=385 \mathrm{~nm}\right)$ has a different maximum from the one in neutral ethanol $\left(\lambda_{\max }=390 \mathrm{~nm}\right)$, again showing a new cationic species. This compound did not fluoresce. Peculiar phosphorescence behavior was observed for 4HTC with spectra and lifetimes suggesting that two species exist in $T_{1}$ (Fig. 2). Most probably, neutral $\left(\mathrm{N}_{\mathrm{T}_{1}}^{*}\right)$ and anion $\left(\mathrm{A}_{\mathrm{T}_{1}}^{*}\right)$ forms are present. Phosphorescence lifetimes, for each solvent, were collected at different wavelengths and first order decays were always obtained (Table 2).

Comparison with the phosphorescence spectra of the ethoxylated thione compound shows that the vibrational structure, found for $4 \mathrm{HTC}$ in ethanol: $\mathrm{HCl}$, is present for all solvents in $4 \mathrm{EtTC}$, although small differences, in intensity, were found (Fig. 2). This suggests that with 4HTC in ethanol and basic ethanol the same $\mathrm{A}^{*}$ species is present and that no cation is found for $4 \mathrm{HTC}$ in $\mathrm{T}_{1}$.

The triplet-triplet absorption spectrum of $4 \mathrm{HTC}$ (Fig. 3) shows singlet depletion in addition to the $\mathrm{T}_{1} \rightarrow \mathrm{T}_{n}$ absorption signal. For $4 \mathrm{HTC}$, in both benzene and ethanol, the spectra are similar in shape and maxima to that obtained for $4 \mathrm{EtTC}$ in benzene. This is compatible with a neutral triplet transient. However, in basic ethanol a new band appears in addition to singlet depletion at $\approx 420 \mathrm{~nm}$, equal to the absorption observed in the ground-state absorption (Fig. 2), suggesting therefore that the new band should be attributed to this species, $\mathrm{A}_{\mathrm{T}_{1} \rightarrow \mathrm{T}_{n}}$.

\subsubsection{H4MC, 7H4MTC and their parent compounds 7Met4MC and 7Et4MTC}

The complex excited state kinetics of $7 \mathrm{H} 4 \mathrm{MC}$ in $\mathrm{S}_{1}$, involving three excited species, was previously considered [5]. For 7Met4MC we have obtained $\tau_{\mathrm{F}}$ values of $0.48,0.46$ and $0.68 \mathrm{~ns}$ in ethanol, acidified ethanol and basic ethanol, respectively. We cannot clearly establish, based on the fluorescence lifetimes, if the cation (ethanol: $\mathrm{HCl}$ mixture) actually has a different value than the neutral and anionic species.

The triplet-triplet absorption spectra of 7H4MC in dioxane (Dx) and acetonitrile $(\mathrm{MeCN})$ consist of single bands with maxima at 460 and $480 \mathrm{~nm}$, respectively (Fig. 4D). The transient spectra obtained in these conditions can be attributed to a neutral form, $\mathrm{N}_{\mathrm{T}_{1} \rightarrow \mathrm{T}_{n}}$, obtained via the $\mathrm{N}_{\mathrm{S}_{0}} \rightarrow \mathrm{N}_{\mathrm{S}_{1}} \stackrel{\mathrm{ISC}}{\rightarrow} \mathrm{N}_{\mathrm{T}_{1} \rightarrow \mathrm{T}_{n}}$ pathway. This is confirmed by comparison with the similar triplet-triplet spectrum of 7Met4MC (Fig. 4E and $\mathrm{F}$ ). In ethanol, acidified ethanol and in dioxane: water 4:1 (Dx: $\left.\mathrm{H}_{2} \mathrm{O} \quad 4: 1\right)$, the $\mathrm{T}_{1} \rightarrow \mathrm{T}_{n}$ absorption spectra of 7H4MC is different from those obtained in $\mathrm{Dx}$ and $\mathrm{MeCN}$, indicating that although the same neutral form is present, there are some differences in the spacing of the $\mathrm{T}_{n}$ states. The similarity between the $\mathrm{T}_{1} \rightarrow \mathrm{T}_{n}$ absorption spectra of $7 \mathrm{H} 4 \mathrm{MC}$ and $7 \mathrm{Met} 4 \mathrm{MC}$ in Dx: $\mathrm{H}_{2} \mathrm{O}$ (1:4), (Fig. 4C and G), suggests that similar 
neutral species are present and that the differences between dioxane and acetonitrile are due to solvent effects on the $\mathrm{T}_{1} \rightarrow \mathrm{T}_{n}$ transitions. The spectrum obtained at $\mathrm{pH}=11.5$ (Fig. $4 \mathrm{~A}$ ) is different, indicating a triplet of the anion, $\mathrm{A}_{\mathrm{T}_{1} \rightarrow \mathrm{T}_{n}}$. In the transient behavior of $7 \mathrm{H} 4 \mathrm{MC}$, no tautomeric triplet, $\mathrm{T}_{\mathrm{T}_{1}} \rightarrow \mathrm{T}_{n}$, was observed. However, we cannot discard the formation of a small amount of $\mathrm{T}_{\mathrm{T}_{1} \rightarrow \mathrm{T}_{n}}$.

The phosphorescence data clearly shows that only two emissive species, $\mathrm{N}_{\mathrm{T}_{1}}{ }^{*}$ and $\mathrm{A}_{\mathrm{T}_{1}}{ }^{*}$ (Table 2), are observed. In the acidified ethanolic mixture the fluorescence spectrum shows emission from $\mathrm{N}^{*}$ and $\mathrm{T}^{*}$ species, whereas in phosphorescence only neutral is observed. An acid-base equilibrium between $\mathrm{N}_{\mathrm{T}_{1} \rightarrow \mathrm{T}_{n}}$ and $\mathrm{A}_{\mathrm{T}_{1} \rightarrow \mathrm{T}_{n}}$ should exist. Although transient absorption data exists for 7H4MC [16], the solvent was not defined, and therefore the nature of the transient cannot be ascertained. However, comparison of the band reported at $510 \mathrm{~nm}$ [16] with our triplet-triplet spectra suggests this is the same as in our mixture of ethanol:HCl 19:1 and Dx: $\mathrm{H}_{2} \mathrm{O}$ 4:1 (Fig. 4). The triplet-triplet absorption spectrum of 7H4MTC in methanol and benzene (Fig. 4H and I), displays a maximum at $510-520 \mathrm{~nm}$. Comparison with the triplet-triplet absorption spectrum of 7Et4MTC (Fig. 4J) supports the idea that the absorbing species should be the neutral, $\mathrm{N}_{\mathrm{T}_{1} \rightarrow \mathrm{T}_{n}}$. The depletion at 300$450 \mathrm{~nm}$, with a maximum at $390-400 \mathrm{~nm}$, equal to the one observed in the ground-state absorption (Fig. 5), strongly supports the idea that the transient spectrum obtained in these conditions is the one of a neutral form, $\mathrm{N}_{\mathrm{T}_{1} \rightarrow \mathrm{T}_{n}}$, obtained via $\mathrm{N}_{\mathrm{S}_{0}} \rightarrow \mathrm{N}_{\mathrm{S}_{1}} \stackrel{\mathrm{ISC}}{\rightarrow} \mathrm{N}_{\mathrm{T}_{1} \rightarrow \mathrm{T}_{n}}$.

Fig. $5 \mathrm{~B}$ shows the ground-state acid-base equilibrium between the neutral and anionic forms of 7H4MTC. Significant differences are observed between phosphorescence in basic ethanol and the other two mixtures, (Fig. 5A, Table 2), indicating that in $\mathrm{T}_{1}$ two species (neutral and anion) are present.

\section{Conclusions}

Significant differences are observed between spectroscopy and photophysics of HCs and their thione analogs: red-shift in the absorption spectra, quenching of fluorescence, increased triplet-triplet absorption, suggesting increased $\mathrm{S}_{1} \sim \longrightarrow \mathrm{T}_{1}$ ISC and a decrease in the phosphorescence lifetime. The long phosphor- escence lifetimes observed for the carbonyl compounds indicate that emission is from a triplet $\pi, \pi^{*}$ state, whilst for the thione compounds the shorter lifetimes indicate that the $T_{1}$ state has $n, \pi^{*}$ character. For the thionyl compounds, the singlet state $S_{1}$ is always $n, \pi^{*}$ whereas for the carbonyl compounds, where some degree of mixing with $\mathrm{S}_{2}\left(\pi, \pi^{*}\right)$ or exchange in the energetic order can occur, it depends on the media. Depending upon $\mathrm{pH}$ and solvent, the compounds can exist in four forms: a cation, a neutral form, an anion and a tautomer (quinone-like canonical form).

\section{Acknowledgements}

The authors acknowledge financial support from Fundação para a Ciência e Tecnologia/Lisbon (PrAXIS/QUI/10137/98). JSM acknowledges Dr H.D. Burrows a critical review of this work.

\section{References}

[1] B.E. Nielsen, Coumarins patterns in the Umbelliferae, in: V.H. Heywood (Ed.), The Biology and Chemistry of the Umbelliferae, Academic Press, London, 1971, pp. 325-336.

[2] G. Lazarova, I. Kostova, H. Neychev, Fitoterapia 64 (1993) 134.

[3] S.C. Haydon, Spec. Lett. 8 (1975) 815.

[4] G. Matolcsy, M. Nádasy, V. Andriska, Pesticide Chemistry, Studies in Environmental Science, vol. 32, Elsevier, Budapest, 1988.

[5] J. Seixas de Melo, A.L. Maçanita, Chem. Phys. Lett. 204 (1993) 556.

[6] E. Bardez, P. Boutin, B. Valeur, Chem. Phys. Lett. 191 (1992) 142.

[7] T. Moriya, Bull. Chem. Soc. Jpn 61 (1988) 1873.

[8] P.E. Zinsli, J. Photochem. 3 (1974) 55.

[9] J. Seixas de Melo, P.F. Fernandes, J.C. Lima, A.L. Maçanita, in preparation.

[10] J. Seixas de Melo, R.S. Becker, A.L. Maçanita, J. Phys. Chem. 98 (1994) 6054.

[11] R.S. Becker, S. Chakravorti, C. Gartner, M.G. Miguel, J. Chem. Soc. Faraday Trans. 89 (1993) 1007.

[12] G. Stricker, V. Subramaniam, C.A.M. Seidel, A. Volkmer, J. Phys. Chem. B 103 (1999) 8612.

[13] M.C. Zerner, in: K.B. Lipkowitz, D.B. Boyd (Eds.), Semiempirical Molecular Orbital Methods, Reviews in Computational Chemistry, VCH, New York, 1991, pp. 313-365.

[14] B.R. Henry, R.V. Hunt, J. Mol. Spec. 39 (1971) 466.

[15] P.T. Chou, M.L. Martinez, S.L. Studer, Chem. Phys. Lett. 188 (1992) 49.

[16] T.G. Pavlopoulos, IEEE J. Quantum Elec. 9 (1973) 510. 
[17] O.S. Wolfbeis, G. Uray, Monatsh. Chem. 109 (1978) 123.

[18] R.S. Becker, Theory and Interpretation of Fluorescence and Phosphorescence, Wiley-Interscience, New York, 1969.

[19] A. Maciejewski, R.P. Steer, Chem. Rev. 93 (1993) 67.

[20] K. Bhattachayya, P.K. Das, V. Ramamurthy, V.P. Rao, J. Chem. Soc. Faraday Trans. 2 (82) (1986) 135.
[21] D.W. Cho, S.G. Kang, Y.H. Kim, M. Lee, D. Kim, M. Yoon, J. Photoscience 2 (1995) 13.

[22] G.J. Yakatan, R.J. Juneau, S.G. Schulman, J. Pharm. Sci. 61 (1972) 749. 